Technical Paper

\title{
A Ripeness Study of Oil Palm Fresh Fruit at The Bunch Different Positions
}

\author{
Rismen Sinambela, Doctoral Student of Graduate School of Agricultural Engineering Science, \\ Faculty of Agricultural Engineering and Technology, Bogor Agricultural University, Bogor 16680, \\ Indonesia. Email: rismensinambela@gmail.com \\ Tineke Mandang, Department of Mechanical and Biosystem Engineering, Faculty of Agricultural \\ Engineering and Technology, Bogor Agricultural University, Bogor 16680, Indonesia. \\ Email: tineke_mandang_2003@yahoo.com \\ I Dewa Made Subrata, Department of Mechanical and Biosystem Engineering, Faculty of Agricultural \\ Engineering and Technology, Bogor Agricultural University, Bogor 16680, Indonesia. \\ Email: dewamadesubrata.ipb@gmail.com \\ Wawan Hermawan, Department of Mechanical and Biosystem Engineering, Faculty of Agricultural \\ Engineering and Technology, Bogor Agricultural University, Bogor 16680, Indonesia. \\ Email: wawanfateta@yahoo.co.id
}

\begin{abstract}
The paper aims to study the position of the optimum oil palm ripeness at the bunch different positions. This information is essential to complete a measurement procedure to detect oil palm fresh fruit bunch (FFB) maturity so that the detection devices can directly measure the optimal mature position as a representative of the entire FFB characteristics. In this study, the oil palm FFB (Elaeis guineensis Jacq. var. tenera) with the various ripeness stages (4 until 24 weeks after anthesis) were collected and divided from three positions, i.e., proximal, central and distal. Moreover, each fruit in each of these positions was subjected to sample preparation to identify water and oil content. The water and oil content were completed based on the oven test method and the Soxhlet extraction technique, respectively. The optimum ripeness position is determined based on the lowest water content and the highest oil content. Based on the analysis, during the process of oil palm maturation occurs a decrease in water content and an increase in oil content. In addition, the average water content of palm fruit (4 until 24 weeks after anthesis) varies greatly depending on its position based on the analysis, i.e., proximal (45.83 $\pm 20.66 \%)$, central $(33.88 \pm 21.18 \%)$ and distal $(41.93 \pm 21.49 \%)$. The average oil content of oil palm fruit (4 until 24 weeks after anthesis) in the central position is higher oil content $(25.13 \pm 14.18 \%)$ compared to the proximal $(13.92 \pm 12.25 \%)$ and distal position $(15.98 \pm 11.64 \%)$. We suspect that the chemical content differences of palm fruit in various positions are due to the inequality of the respiration rate and ethylene production throughout FFB. In addition, overall it can be concluded that the fruit in the central FFB position has an optimal ripeness level compared to the proximal and distal position. Thus, the measurement position recommended in evaluating palm maturity is at the central position of FFB.
\end{abstract}

Keywords: Fresh fruit bunch, oil palm, optimum ripeness position. 


\section{Introduction}

Indonesia is the largest country in the production and export of oil palm products, which is more wellknown as crude palm oil (CPO) (Makky and Soni 2013a, 2013b, 2014, Cherie et al. 2015, Makky 2016, Makky et al. 2018, Cherie et al. 2019). Moreover, to produce high-quality CPO, fresh fruit bunches in oil palm must be harvested at optimal mature conditions (Misron et al. 2017). However, over the past decade, the identification of the maturity level of oil palm fresh fruit bunches (FFB) is still a major unresolved issue in the palm oil industry (Saeed et al. 2013). Generally, the FFB maturity level is divided into three categories, namely unripe, ripe and overripe (Saeed et al. 2012, Makky et al. 2014c). So far, in determining the FFB ripeness is still done manually and traditionally using human vision by trained workers. The common practice used as a bunch ripeness is based on the number or percentage of detached fruits per bunch (Makky and Soni 2014). The maximum oil yield is found only when the fruit is about to be detached from the bunch. Of course, this maturity evaluation has weaknesses such as subjective and qualitative judgment which leads to inconsistency of measurement. Therefore, this problem attracted the attention of researchers to develop accurate techniques in evaluating the maturity level of oil palm. Some proposed techniques involved oil content measurement, inductive and image processing (Saeed et al. 2012, Makky and Soni 2014, Misron et al. 2017, Salambue et al. 2018).

Based on state of the art, scientist reported that the maturity level of FFB could be identified based on its chemical content such as water and oil content in the fruit (Makky and Soni 2014, Iqbal et al. 2015). Both parameters provide distinctive characteristics according to FFB maturity. For example, mature FFB with ripeness stage of 18-21 weeks after anthesis has higher oil content (58.30\%) than unripe FFB in 7 weeks after anthesis (5.90\%) (Misron et al. 2017). Thus, those parameters have been adopted as an approach to predict the maturity level of oil palm. However, the accuracy of various maturity detection devices is still relatively low, which is around $75-85 \%$ (Saeed et al. 2012, lqbal et al. 2015, Salambue et al. 2018). This accuracy can be improved by investigating the position of the optimum ripe fruit in FFB as a first step before the maturity measurement is carried out. The position of the fruit may be at the proximal, central and distal locations of FFB. Therefore, the user can focus the measurement on the position of the optimum ripe fruit to obtain the overall characteristics of FFB, and the performance of sophisticated devices currently present will be even more precise.

However, no knowledge has ever been reported concerning the optimum position as a reference for evaluating maturity in each FFB. This information is critical to reveal due to each FFB consists of many fruits and the possibility of its maturity level varies greatly based on its position. Therefore, based on the above issues, the purpose of this study is to identify the position of the optimum oil palm ripeness at the bunch of different positions. Further, the impact of this study is to complete a measurement procedure in evaluating oil palm maturity.

\section{Material and Methods}

\section{Fruit collection}

The selection of oil palm fruit in FFB was standardized throughout the research. A total of six FFBs from tenera varieties (Elaeis guineensis Jacq. var. tenera) were harvested from the Oil Palm Cikasungka Plantation, Bogor, Indonesia. To determine the stages of ripeness, oil palm trees are marked first when FFB displayed many flowers (a)

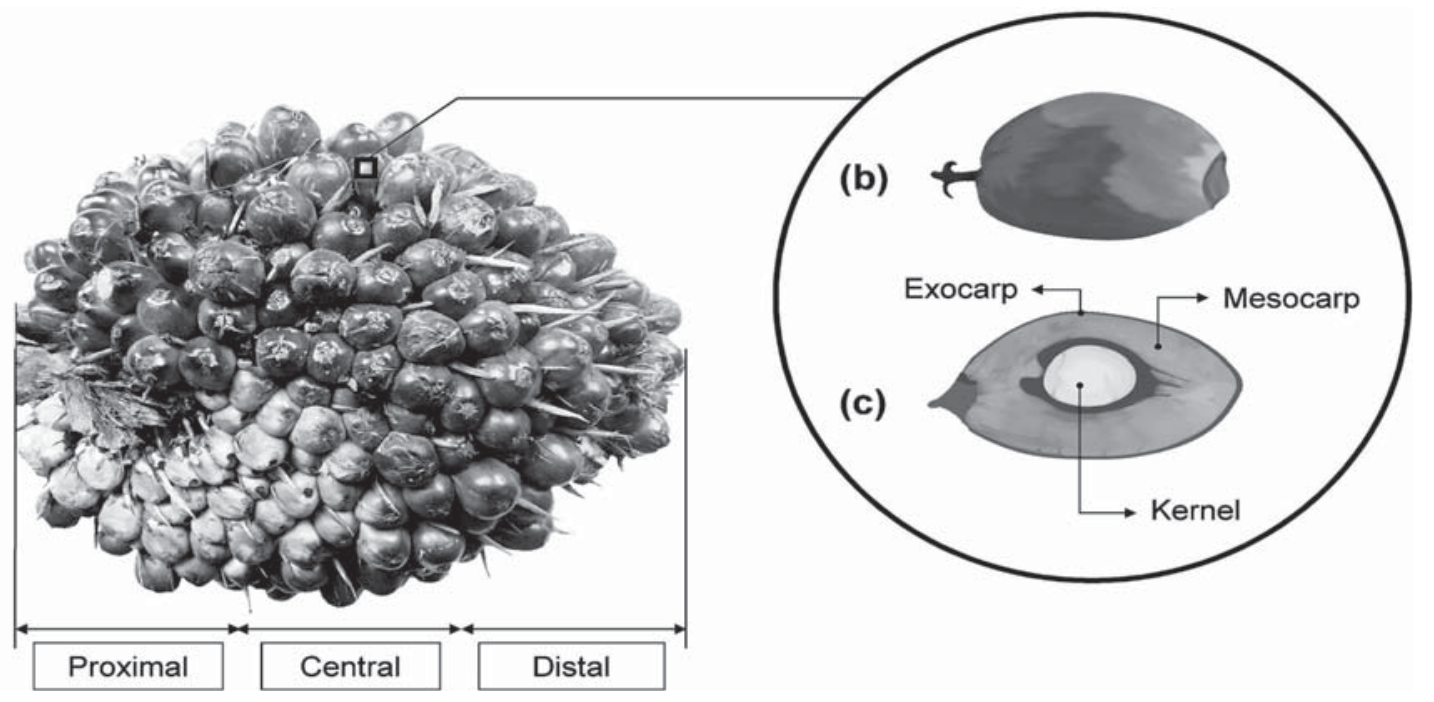

Figure 1. (a) division of FFB position; (b) oil palm fruit; (c) cross-section of oil palm fruit. 
at full anthesis. This was assisted by professional labours in the plantation. Overall FFB collected has various stages of ripeness, i.e., 4, 8, 12, 16, 20 and 24 weeks after anthesis. According to Abbas (1994), 1-20 weeks are grouped as unripe fruit, whereas 21-24 weeks are classified as ripe fruit. In this study, each FFB has a length of about $50 \pm$ $5 \mathrm{~cm}$. Furthermore, the FFB region is divided into three positions namely proximal, central and distal (Figure 1a). A total of 4 fruits from outer part of the FFB is collected from each position and the tissue mesocarp was subjected to sample preparation to identify the chemical content of the fruit (Figure 1c). The process of fruit selection is strictly selected based on the relatively the same colour, size, and weight. Besides the fruits were also ensured in a condition without a bruise. A total of 72 fruits were identified for their chemical content including water and oil content to find the optimal mature position in FFB.

\section{Analysis of Chemical Content in Fruit}

In this study, water and oil content were selected as a parameter to identify the optimum mature position in FFB. This analysis must be completed at Agricultural Postharvest Laboratory (BB-Pascapanen) on the same day when the fruit is taken from FFB to avoid inconsistency and contamination. The detailed stages of water and oil content analysis are as follows:

\section{Water content}

The water content of fruit was determined using an oven test method (SNI 01-2891-1992 standard) (Mandang et al. 2018). The main principle in this method is to evaporate the water in the fruit by using heating at a temperature of $105^{\circ} \mathrm{C}$ for 3 hours. This process is repeated until the sample mass become constant. Difference between sample weight before and after heating is considered as water content.

\section{Oil content}

The oil content measurement was completed based on the Soxhlet extraction technique (standard SNI 01-2891-1992). A total of $2 \mathrm{~g}$ of the sample from the oil palm fruit is connected with a Soxhlet extraction tool (SZC-D 13 soxhlet extraction) at a temperature of $80^{\circ} \mathrm{C}$ for one hour. Next, the samples were extracted using petroleum ether solvent for 6 hours and dried at $105^{\circ} \mathrm{C}$ for 3 hours. This process is repeated until the sample mass become constant. The oil content is expressed in the ratio between the sample weight difference before and after extraction and the initial sample weight.

\section{Statistical analysis and ripeness evaluation}

Water and oil content parameter in each FFB position were subjected to two-way analysis of variance ANOVA, with Microsoft Office Excel 2013 (Microsoft, Washington, DC, USA) and the comparison of means was performed with Turkey's test at $p<0.05$. Also, the optimum maturity position in FFB was determined based on the lowest water content and the highest oil content.

\section{Results}

\section{Chemical Content During Ripeness Process}

The water and oil content in oil palm fruit during the ripening process has unique characteristics. In general, during the process of oil palm maturation occurs a decrease in water content and an increase in oil content (Figure 2). Water content in oil palm

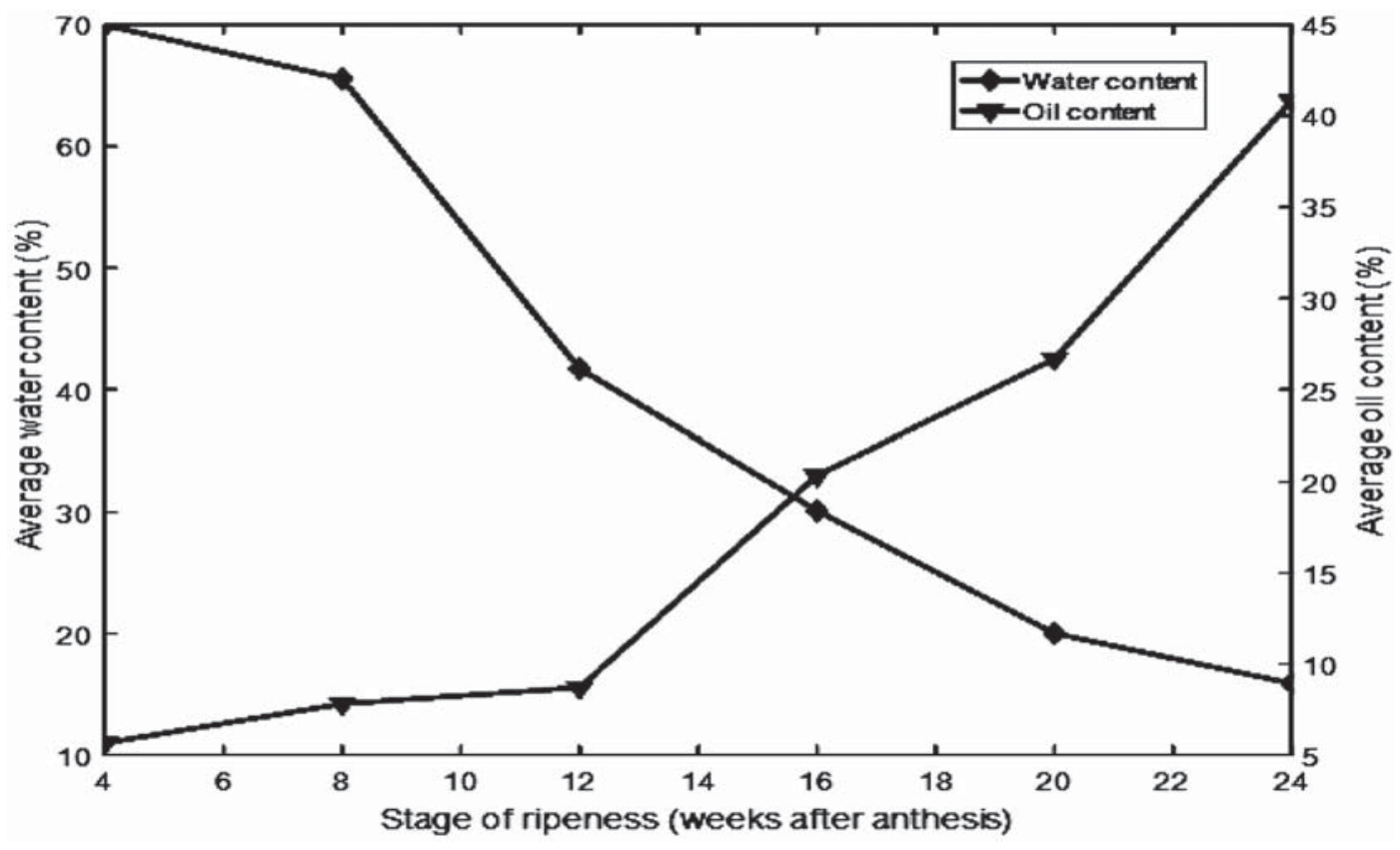

Figure 2. Water and oil content characteristics during ripeness process. 
gradually decreases during maturation, i.e., from $69.99 \%$ (4 weeks) to $15.90 \%$ (24 weeks). While oil content increases with increasing maturation process. The changes of oil content increase gradually from $5.67 \%$ (4 weeks) to $40.84 \%$ (24 weeks). The same characteristics have been discovered by lqbal et al. (2015) regarding changes in water and oil content during the maturation process of oil palm.

Based on the analysis, FFB harvested in various stage of ripeness (4-24 weeks after anthesis) had average water and oil content of $40.55 \pm 5.51 \%$ and $18.34 \pm 4.87 \%$, respectively. There's not a lot of difference from the previous research report regarding palm fruit maturity, i.e., about $35 \%$ for water content and $20 \%$ for oil content (Iqbal 2015). The results of this study confirm that the FFB at 24 weeks after anthesis is considered as optimal harvest time to obtain high oil content.

\section{Optimum Ripeness Position}

The chemical content of water and oil content varies significantly throughout the FFB position. Figure 3 and 4 show water and oil content from oil palm fruit harvested in various FFB positions such as proximal, central and distal. Based on the analysis, the average water content of palm fruit (4-24 weeks after anthesis) varies greatly depending on its position, i.e., proximal (45.83 $\pm 20.66 \%)$, central $(33.88 \pm 21.18 \%)$ and distal $(41.93 \pm 21.49 \%)$. The results of this study confirm

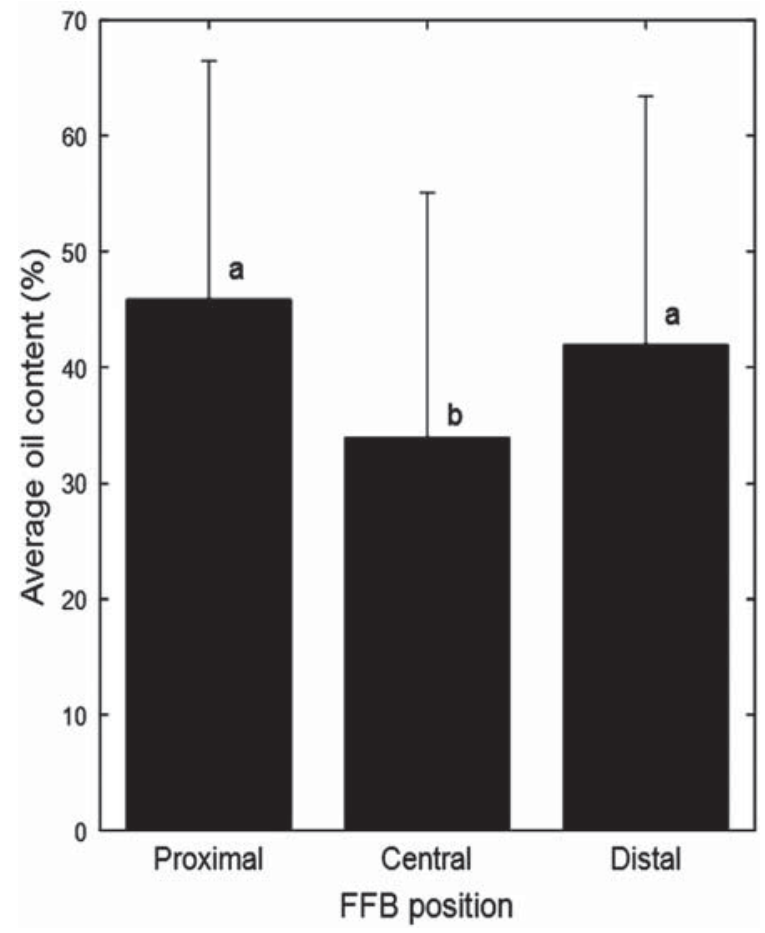

Figure 3. Comparison of water content in various FFB positions. The different notation on the same chemical component indicated the significant value, Turkey's test at $p<0.05$. that the palm fruit at the central position has the lowest water content compared to the proximal and distal position. Moreover, regarding oil content, the average oil palm fruit (4-24 weeks after anthesis) in the central position has higher oil content $(25.13 \pm$ $14.18 \%$ ) compared to the proximal (13.92 $\pm 12.25 \%)$ and distal position (15.98 $\pm 11.64 \%)$. Statistically, the chemical content (water and oil content) in the central position has a significant difference $(p<0.05)$ against the proximal and distal position. Whereas the water and oil content in the proximal and distal position, both did not differ significantly. According to Fourie et al. (1991), variations in chemical content in various fruit positions can differ depending on many factors, mainly because of the environmental conditions, technology, climate, cultivars, etc.

The maturity level of oil palm fruit in FFB varies greatly and will not mature in the same circumstances. The results of this study indicate that the central position in FFB has optimal maturity. This is evidenced by the lowest water content and the highest oil content. Misron et al. (2017) reported that the more mature the oil palm fruit, the higher the oil content; thus, the water content in fruit would decrease further. According to Oh and Kamaruddin (1989), oil content in FFB is formed significantly from the 15th week of anthesis and continues to increase until the 20th week.

As explained in the introduction section, the knowledge about the optimal mature position will be used as a reference to evaluate the FFB ripeness.

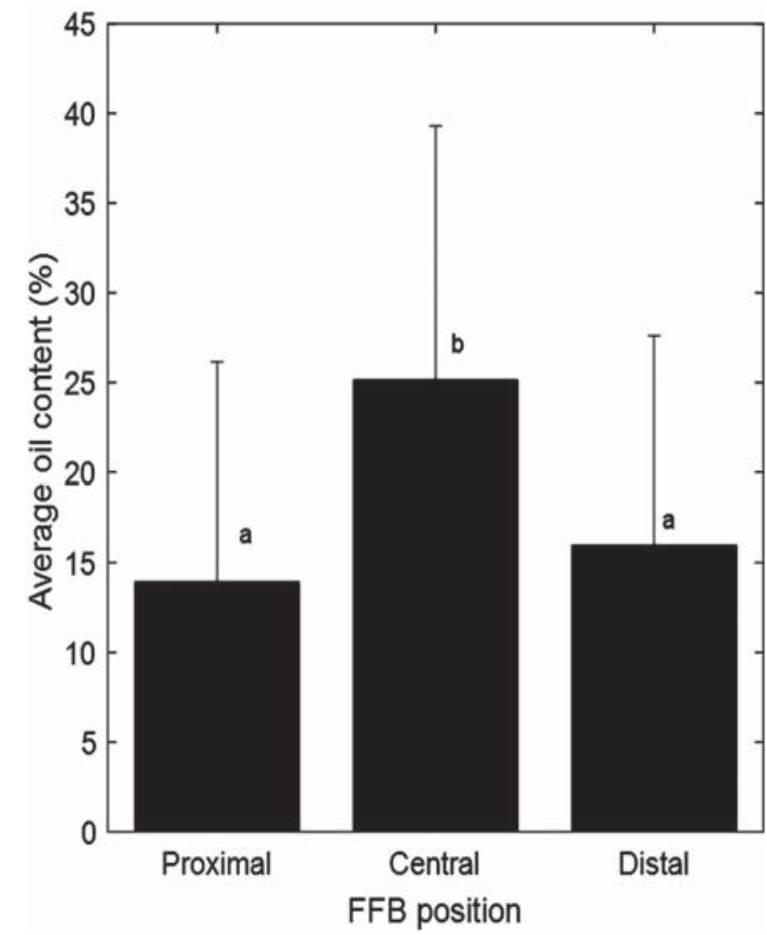

Figure 4. Comparison of oil content in various FFB positions. The different notation on the same chemical component indicated the significant value, Turkey's test at $p<0.05$. 
This study revealed that the optimum mature position is at the central position of FFB. Thus, the palm ripeness detection device can directly measure in the central position as a representative of the overall FFB characteristics.

\section{Discussion}

The main goal of this investigation was to identify the position of the optimum oil palm ripeness at the bunch different positions. The results of this study indicate that the water and oil content in palm fruit varies greatly depending on the fruit position. Based on the analysis, the central position in FFB has an optimal level of maturity compared to the proximal and distal position. Theoretically, the fruit maturity is influenced by two main factors including respiration rate and ethylene production (Tranbarger et al. 2011, Makky et al. 2014b, 2014a). According to Nualwijit and Lerslerwong (2014), oil palm is classified as climatic fruit, where during the ripening process, there is an increase in both respiration rate and ethylene production. The uneven of respiration rate and ethylene production in FFB leads to differences in the chemical content of palm fruit in various positions. The water and oil content stored in cells in the mesocarp generally decreased and increased respectively with increasing stages of ripening.

This investigation confirms that the occurrence of water deficit is a fundamental metabolic transformation occurring in ripening fruit. Creation of water deficit appears to be an autonomous and developmentally related process and, apparently, a universal phenomenon in ripening fruit (Frenkel and Hartman 2012). Usually, the water content during the ripening process often decreases due to the transformation of starch into reducing sugars and consequently an increase of osmotic potential that induces the movement of water from the exocarp to the mesocarp (Aghofack-Nguemezi et al. 2008). Also, as the fruit approaches maturity, the oil content formation increases rapidly to about $50 \%$ of mesocarp weigh (Poku 2002). This oil content is stored in a particular place inside the mesocarp known as lipid bodies. Generally, lipid bodies are small and spherical in shape with diameters ranging from 0.50-2.5 $\mu \mathrm{m}$ (Ho et al. 2014). In the ripening process, the oil content is usually determined by the hydrolysis by lipolytic enzymes process (Poku 2002, Iqbal et al. 2015). The lower the content of lipolytic enzymes, the higher the oil content in palm fruit. Concomitantly, Abbas (1994) explained that the accumulation of oil in the mesocarp has almost the same rate with the decrease of water content. Therefore, the close relationship between the water and oil content in mesocarp gives a possibility as a parameter to gauge ripeness.

The impact of this study is to complete measurement procedure in detecting the maturity of palm fruit due to the various existing devices (Saeed et al. 2012, Makky and Soni 2014, Misron et al. 2017) are not paying attention to the optimal mature position as a measurement point. For example, Saeed et al. (2012), use the whole position (proximal, central and distal) to evaluate palm maturity and show an accuracy of $80 \%$. Based on the analysis, the recommended measurement position in evaluating oil palm maturity is in the central position of FFB. The proximal and distal position is not used because it has less significantly different chemical content. Through measurements that only focus on the central FFB area, hopefully, this can improve the performance of the palm maturity detection device.

\section{Conclusion}

This work revealed the critical information regarding the optimum position of ripe fruit at various positions in FFB (proximal, central and distal). This optimum maturity position is evaluated based on the lowest water content and the highest oil content. Based on the analysis, the average water content of palm fruit varies greatly depending on its position, i.e., $(45.83 \pm 20.66 \%)$, central (33.88 $\pm 21.18 \%)$ and distal $(41.93 \pm 21.49 \%)$. Besides, in terms of oil content, the average oil palm fruit in the central position has higher oil content $(25.13$ $\pm 14.18 \%$ ) compared to the proximal (13.92 \pm $12.25 \%)$ and distal position (15.98 $\pm 11.64 \%)$. The results of this study clearly showed that the fruit in central FFB area had an optimal maturity level compared to the proximal and distal position. This is a precious finding as a reference for evaluating the FFB maturity. Thus, the palm maturity detection device can directly measure the central position as a representative characteristic of the overall FFB.

\section{Acknowledgments}

The authors would like to acknowledge the Indonesia Endowment Fund for Education (LPDP) and The Ministry of Research, Technology and Higher Education of the Republic of Indonesia for providing financial support (project no. PRJ-6173 / LPDP.3/2016).

\section{Reference}

Abbas, Z. 1994. Amicrostrip sensor for determination of harvesting time for oil palm fruits (PhD Thesis) Universiti Pertanian Malaysia.

Aghofack-Nguemezi, J., G. Kanmegne, J. Mankaabiengwa. 2008. Effects of auxins and edible oils on the ripening and water Content of banana fruits. J. Plant Sci. 3(4): 248-254. 
Cherie, D., S. Herodian, U. Ahmad, T. Mandang, M. Makky. 2015. Optical characteristics of oil palm fresh fruits bunch (FFB) under three spectrum regions influence for harvest decision. IJASEIT. 5(3): 104-112.

Cherie, D., R. Rini, M. Makky. 2019. Determination of the optimum harvest window and quality attributes of oil palm fresh fruit bunch using nondestructive shortwave infrared spectroscopy. In: AIP Conference Proceedings. pp 020034.

Frenkel, C., T.G. Hartman. 2012. Decrease in fruit moisture content heralds and might launch the onset of ripening processes. Journal of food science. 77(10): S365-S376.

Ho, L.S., A. Nair, H.M. Yusof, H. Kulaveerasingam, M.S. Jangi. 2014. Morphometry of lipid bodies in embryo, kernel and mesocarp of oil palm: Its relationship to yield. American Journal of Plant Sciences. 5(09): 1163.

Iqbal, Z. 2015. Pendugaan Kandungan Kimia Tandan Buah Segar (TBS) Kelapa Sawit Menggunakan Spektroskopi NIR. Bogor: IPB University.

Iqbal, Z., S. Herodian, S. Widodo. 2015. Pendugaan Kadar Air dan Total Karoten Tandan Buah Segar (TBS) Kelapa Sawit Menggunakan NIR Spektroskopi. Jurnal Keteknikan Pertanian. 2(2).

Makky, M. 2016. Trend in non-destructive quality inspections for oil palm fresh fruits bunch in Indonesia. International Food Research Journal. 23.

Makky, M., K.A. Paschalidis, K. Dima, A. Mangganaris. 2014a. Harnessing untapped bio-ethylene sources from tomatoes climacteric effluent. In: Proc. International Conference on Agricultural, Environmental and Biological Sciences (AEBS-2014) April. pp 24-25.

Makky, M., K.A. Paschalidis, K. Dima, A. Mangganaris. 2014b. A new rapid gas chromatographic method for ethylene, respirational, and senescent gaseous production of climacteric fruits stored in prolonged low temperature. In: Proc. International Conference on Agricultural, Environmental and Biological Sciences (AEBS-2014) April. pp 24-25.

Makky, M., P. Soni. 2013a. Development of an automatic grading machine for oil palm fresh fruits bunches (FFBs) based on machine vision. Computers and electronics in agriculture. 93: 129-139.

Makky, M., P. Soni. 2013b. Towards sustainable green production: exploring automated grading for oil palm fresh fruit bunches (FFB) using machine vision and spectral analysis. International Journal on Advanced Science, Engineering and Information Technology. 3(1): 1-5.
Makky, M., P. Soni. 2014. In situ quality assessment of intact oil palm fresh fruit bunches using rapid portable non-contact and non-destructive approach. Journal of Food Engineering. 120: 248-259.

Makky, M., P. Soni. V.M. Salokhe. 2014c. Automatic non-destructive quality inspection system for oil palm fruits. International Agrophysics. 28(3): 319-329.

Makky, M., D. Yanti, I. Berd. 2018. Development of Aerial Online Intelligent Plant Monitoring System for Oil Palm (Elaeis guineensis Jacq.) Performance to External Stimuli. International Journal on Advanced Science, Engineering and Information Technology. 8(2): 579-587.

Mandang, T., R. Sinambela, N. Pandianuraga. 2018. Physical and mechanical characteristics of oil palm leaf and fruits bunch stalks for biomulching. In: IOP Conference Series: Earth and Environmental Science. pp 012015.

Misron, N., N. Aliteh, N. Harun, K. Tashiro, T. Sato, H. Wakiwaka. 2017. Relative estimation of water content for flat-type inductive-based oil palm fruit maturity sensor. Sensors. 17(1): 52.

Nualwijit, N., L. Lerslerwong. 2014. Post harvest ripening of oil palm fruit is accelerated by application of exogenous ethylene. Songklanakarin J. Sci. Technol. 36: 255-259.

Oh, F.C., Z. Kamaruddin. 1989. Comparison of palm kernel stearin SFC measurements at $30^{\circ} \mathrm{C}$ by wideline and pulse NMR. Elaeis. 1(2): 103-108.

Poku, K. 2002. Small-scale palm oil processing in Africa: Food \& Agriculture Org.

Saeed, O.M.B., S. Sankaran, A.R.M. Shariff, H.Z.M. Shafri, R. Ehsani, M.S. Alfatni, M.H.M. Hazir. 2012. Classification of oil palm fresh fruit bunches based on their maturity using portable four-band sensor system. Computers and Electronics in Agriculture. 82: 55-60.

Saeed, O.M.B., A.R.M. Shariff, A.R.B. Mahmud, H.Z.M. Shafri, M.S. Alfatni, M. Aouache, R. Ehsani. 2013. Ripeness detection of oil palm fresh fruit bunches using 4-band sensors. Advanced Science Letters. 19(12): 3468-3472.

Salambue, R., A. Adnan, M. Shiddiq. 2018. Investigation of the ripeness of oil palm fresh fruit bunches using bio-speckle imaging. In: Journal of Physics: Conference Series. pp 012071.

Tranbarger, T.J., S. Dussert, T. Joët, X. Argout, M. Summo, A. Champion, D. Cros, A. Omore, B. Nouy, F. Morcillo. 2011. Regulatory mechanisms underlying oil palm fruit mesocarp maturation, ripening, and functional specialization in lipid and carotenoid metabolism. Plant physiology. 156(2): 564-584. 